2014-09

Evaluating the application of

research-based guidance to the design of an emergency preparedness leaflet

Hellier, Elizabeth

http://hdl.handle.net/10026.1/2912

10.1016/j.apergo.2013.10.002

Applied Ergonomics

Elsevier BV

All content in PEARL is protected by copyright law. Author manuscripts are made available in accordance with publisher policies. Please cite only the published version using the details provided on the item record or document. In the absence of an open licence (e.g. Creative Commons), permissions for further reuse of content should be sought from the publisher or author. 


\title{
Evaluating the application of research-based guidance to the design of an emergency preparedness leaflet
}

\author{
E. Hellier ${ }^{\mathrm{a}, *}$, J. Edworthy ${ }^{\mathrm{a}}$, L. Newbold ${ }^{\mathrm{a}, \mathrm{b}}$, K. Titchener ${ }^{\mathrm{a}, \mathrm{c}}$, M. Tucker $^{\mathrm{a}}$, E. Gabe-Thomas ${ }^{\mathrm{a}, \mathrm{d}}$ \\ ${ }^{a}$ Centre for Brain, Behaviour and Cognition, School of Psychology, University of Plymouth, Plymouth PL4 8AA, UK \\ ${ }^{\mathrm{b}}$ Mood Disorders Centre, University of Exeter, UK

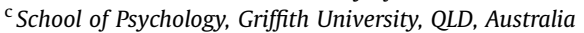 \\ ${ }^{\mathrm{d}}$ School of Psychology, University of Bath, UK
}

\section{A R T I C L E I N F O}

\section{Article history:}

Received 7 September 2012

Accepted 7 October 2013

\section{Keywords:}

Risk communication

Emergency preparedness

\begin{abstract}
A B S T R A C T
Guidelines for the design of emergency communications were derived from primary research and interrogation of the literature. The guidelines were used to re-design a nuclear emergency preparedness leaflet routinely distributed to households in the local area. Pre-test measures of memory for, and selfreported understanding of, nuclear safety information were collected. The findings revealed high levels of non-receipt of the leaflet, and among those who did receive it, memory for safety advice was poor. Subjective evaluations of the trial leaflet suggested that it was preferred and judged easier to understand than the original. Objective measures of memory for the two leaflets were also recorded, once after the study period, and again one week or four weeks later. Memory for the advice was better, at all time periods, when participants studied the trial leaflet. The findings showcase evaluation of emergency preparedness literature and suggest that extant research findings can be applied to the design of communications to improve memory and understandability.

Statement of relevance: Studies are described that showcase the use of research-based guidelines to design emergency communications and provide both subjective and objective data to support designing emergency communications in this way. In addition, the research evaluates the effectiveness of emergency preparedness leaflets that are routinely distributed to households. This work is of relevance to academics interested in risk communication and to practitioners involved in civil protection and emergency preparedness.
\end{abstract}

(C) 2013 Elsevier Ltd and The Ergonomics Society. All rights reserved.

\section{Introduction}

The 2001 Radiation Emergency Preparedness and Public Information Regulations (REPPIR) require that UK installations which have the potential to release specified levels of radiation warn and inform the general public about health protection measures in the event of an emergency. The distribution of emergency preparedness literature is a common means of fulfilling this requirement to warn and inform the public in preparedness for nuclear and other civil emergencies. Such literature is often produced to fulfil mandatory requirements, with little known about how effective it is in terms of being understandable, informative, useful, and encouraging the desirable compliant behaviour(s). The content, design and format of such literature tends to be ad hoc, rather than being based on research evidence to guide the design and presentation of information. While there are guidelines for the design of emergency

\footnotetext{
* Corresponding author.

E-mail address: ehellier@plymouth.ac.uk (E. Hellier).
}

communications (e.g. REPPIR, 2001; Centres for Disease Control \& Prevention, 2002; Covello, 2003; Wray et al., 2004), in the UK they tend to focus on the statutory requirements to include particular pieces of information (such as technical information), rather than being based on research evidence as to what people need to know, how it should be presented, and how best to encourage compliant behaviour(s). In the US the guidelines are based on what is considered best practice and lessons learnt from prior incidents, and what can be predicated on the basis of theories such as Mileti and Sorensen's Warning Response Model (Sorensen et al., 1987; Sorensen, 2000; Peek and Mileti, 2002) and the Protective Action Decision Model (Lindell and Perry, 1992, 2004, 2012), along with risk communication and behavioural perspectives (Wray et al., 2004). In the wake of events such as 9/11 and the anthrax attacks in 2001, there is a growing literature base from the US on the design and development of emergency communications based on case studies (e.g. Shore, 2003; Vanderford, 2003), and also on experience of hazard communication for environmental hazards such as hurricanes (e.g. Lindell and Perry, 2004; Kang et al., 2007). There is also a

0003-6870/\$ - see front matter (c) 2013 Elsevier Ltd and The Ergonomics Society. All rights reserved.

http://dx.doi.org/10.1016/j.apergo.2013.10.002 
body of primary research emerging that seeks to address information needs and preferences specifically with regard to emergency communications (e.g. Henderson et al., 2004; Wray and Jupka, 2004; Becker, 2004). There still remains a need for rigorous evaluation of practice guidelines and the communications derived from them, and also to add to the research database that underpins guidelines (e.g. Rudd et al., 2003). One way of contributing to this effort is to incorporate extant research from other fields that is applicable to the design of emergency communications and can contribute to the evidence-base underpinning guidelines, from fields such as the design of warning labels, signs and leaflets, risk perception, and persuasive communications.

For example there is a great deal of research exploring the influence of design variables on the effectiveness of risk communications focused on warning labels, signs and leaflets. The contexts have varied from on-product warning labels, through workplace warning signs to longer text-based warning information such as patient information leaflets. This research has identified a range of design variables that influence the effectiveness of the communication, including information content (e.g. Wogalter et al., 1987; Mileti and Sorensen, 1990; Wogalter et al., 2002; Edworthy et al., 2004), use of colour and pictorials (e.g. Chapanis, 1994; Adams and Edworthy, 1995; Braun and Silver, 1995; Costello et al., 2002; Wogalter et al., 2002; O'Hegarty et al., 2006), and general formatting issues such as font size (e.g. Adams and Edworthy, 1995; Bernardini et al., 2001) and numerical vs. linguistic -based presentation of risk likelihood (e.g. Berry et al., 2004; Knapp et al., 2004). The way in which a warning communication is worded has also been shown to be an important determinant of outcomes such as believability, perceived hazard, trust and compliance. Important wording variables associated with these outcomes include explicitness (Laughery et al., 1991; Frantz, 1994; Taylor and Bower, 2004); framing (e.g. deTurck and Goldhaber, 1989; Levin et al., 1998; Krishnamurthy et al., 2001; Shiv et al., 2004); reading level (e.g Harrison and Bakker, 1998; Bradley et al., 1994) and the use of probabilistic or definitive statements (e.g. Heaps and Henley, 1999; Costello et al., 2002; Edworthy et al., 2004).

Other research has considered the relative merits of print, audio and audiovisual communication media for delivering risk communications (e.g. Furnham et al., 1990; Wogalter and Young, 1991; Barlow and Wogalter, 1993; Moseley et al., 2006) as well as the population's access to different media (e.g. Davie et al., 2004). Research has also consistently shown that different possible attributed sources of risk information differ in perceived characteristics such as trustworthiness, credibility, and expertise (e.g. Slovic, 1993).

Another important set of factors for consideration in the design of emergency communications are those associated with characteristics of the intended recipients. The prior understanding that recipients have of a particular risk (their mental model) as well as more general tendencies that they exhibit in terms of the way they perceive risk have been shown to be important likely determinants of subsequent behaviour (e.g. Pidgeon et al., 1992; Atman et al., 1994; Bostrom et al., 1994; MacGregor et al., 1994; Lemyre et al., 2006). In addition, individual differences such as gender and age affect how a communication is received (e.g. Davidson and Freudenburg, 1996; Bier, 2001; Grabe and Kamhawi, 2006), as does recipients' memory capacity for it (e.g. Singh et al., 1994; Morrow et al., 1999; Leahy et al., 2003; Hancock et al., 2005). Individuals' literacy levels have also been identified as a potential barrier to understanding emergency communications, with calls to match communications to the reading level of the target population (e.g. Parker and Gazmararian, 2003; Rudd et al., 2003).

It is evident then that there is well documented research evidence from a variety of other domains available to guide the design of emergency preparedness information. Here we studied the emergency preparedness literature routinely distributed by a nuclear site operator to houses within a $2 \mathrm{~km}$ radius of the site. The nuclear safety information leaflet (NSIL) they distributed was designed to satisfy the requirements of REPPIR which require that the public are regularly informed about possible risks associated with radiation, but does not offer guidance on how the information is best presented. The NSIL was used as a tool to test the efficacy of guidelines derived from extant research and used to design an alternative leaflet. Thus we aim to add to the evidence-base underpinning guidance for effective emergency communications, and to respond to calls for the effectiveness of such communications, and the guidelines that underpin them, to be evaluated (Bartholomew et al., 2001; Wogalter et al., 2002; Becker, 2011). In addition we were able to explore the effectiveness of leaflet distribution as a means of encouraging emergency preparedness.

Initial baseline measures were collected to record the target population's memory for, and self-reported understanding of, nuclear safety information. This understanding was based upon their general knowledge and also upon the previous NSIL distribution of 2005 , and so these measures afforded an opportunity to evaluate the effectiveness of periodic distributions of emergency preparedness information to households. During the intervention phase, a trial leaflet was designed on the basis of research evidence and focus group evaluations of the original NSIL. The trial leaflet that was developed incorporated much of what would be predicted, on the basis of research evidence, to be best practice in the design of emergency communications. A field evaluation of the trial leaflet was conducted by asking respondents who had received both the trial leaflet and the NSIL to compare them on subjective dimensions. Objective measures of memory for the two leaflets were also recorded. The three phases of study, the baseline measurement, the intervention, and the evaluations, are described below.

\section{Baseline measurement}

The site operators are required by the 2001 REPPIR to deliver nuclear safety information to all households within a $2 \mathrm{~km}$ radius of the site (the public information zone, PIZ) every 3 years. The purpose of these deliveries is to ensure that local residents are informed about possible risks from the site and the appropriate measures to take in the event of an incident. The aim of this phase of study was to record baseline measures of memory for the nuclear safety information and compliance with the preparedness instructions among the population who received the last leaflet delivery (July 2005) prior to our measures. In this way it was possible to evaluate the effectiveness of periodic distributions of emergency preparedness literature.

\subsection{Method}

\subsubsection{Participants}

A sample of 3886 households in the PIZ was selected. Households were selected so that higher and lower income households were equally represented. This was achieved using super output areas (SOAs). A SOA is the smallest geographical area for which UK Government Census data is available, and on the basis of census data a SOA can be defined in terms of the socioeconomic status of the households within it. There were 16 SOAs completely within the PIZ. A sample of SOAs was selected for study, three representing higher income households and three representing lower income households. The assignment of an SOA as indicating higher or lower income was determined on the basis of the 2001 Census by considering variables such as employment status, home ownership, level of unemployment, and educational qualifications. A full list of 
the addresses which fell within each SOA was obtained to ensure delivery to all households in the area.

\subsubsection{Materials}

A questionnaire was designed to measure the effectiveness of the NSIL last delivered in July 2005. In order for an emergency communication to be effective, it must be perceived, received, understood, remembered, and complied with (Wogalter et al., 1999). The baseline questionnaire was structured to assess these specific components of by asking whether or not respondents had received the leaflet $(\mathrm{Y} / \mathrm{N} / \mathrm{DK})$ and had read and understood it (Likert-type scales from 1: None to 8: All). It would not normally be easy to measure compliance with emergency preparedness instructions, however the NSIL asked recipients to keep their leaflet in a safe place for future reference, affording us an opportunity to ask whether they still had their leaflet, and so obtain a direct measure of compliance. Respondents were also asked to free recall the emergency-related safety advisories presented in the NSIL (for which direct compliance measures were not possible, and memory was deemed to be a useful measure since it is a pre-requisite for compliance). Demographic details were also collected.

\subsubsection{Procedure}

The questionnaires were hand delivered to the 3886 households from the six selected SOAs in the PIZ. The questionnaires were delivered by four distributors on two consecutive days in December 2007. They were posted through letter boxes ensuring that multiple occupancy households were provided with a questionnaire for each residential unit. The questionnaires were delivered in envelopes containing the questionnaire, a cover letter of explanation, and a return freepost envelope. Respondents were invited to take part in a prize draw as an incentive to return their questionnaires. There were four prizes of $£ 100$, winners were selected by random draw from the respondents.

\subsection{Results $\mathcal{E}$ discussion}

\subsubsection{Demographic data and response rate}

631 Questionnaires were returned (16.5\%, response rate). $42.6 \%$ of respondents were male and $55.3 \%$ were female $(2.1 \%$ did not specify their gender). Respondents' ages ranged from 19 to 98 years $(M=53.2$ years $)$.

\subsubsection{Receipt of NSIL}

The NSIL is distributed every three years and the last two deliveries prior to our study were in July 2005 and July 2002. It was likely that some the respondents would have moved into the PIZ since July 2005, and so receipt of the leaflet was examined as a function of when respondents moved into the PIZ. 619 Respondents specified their length of residency in the area and whether or not they had received a leaflet. They were divided into three groups according to length of residency; residents who had moved into the area since July 2005 (resident $0-30$ months, $N=108$ ), those who had moved into the area between July 2002 and July 2005 (resident 31-66 months, $N=69$ ), and those who had lived in the area since before July 2002 (resident $67+$ months, $N=442$ ).

It is unsurprising that the majority of respondents in the $0-30$ months (87\%) group had not received a leaflet since they had moved into the area since the last distribution. What is more noteworthy is that $46 \%$ of respondents in the 31-66 month group (who should have received the leaflet once) and $22 \%$ of the respondents in the $67+$ month group (who should have received the leaflet at least twice) reported never having received the leaflet.

\subsubsection{Reading NSIL}

346 Respondents indicated how much of the leaflet they had read. The majority of respondents (55.5\%) reported having read all of the information in the leaflet, with the remaining response categories being marked by between $4 \%$ and $9 \%$ of respondents.

\subsubsection{Self-reported understanding NSIL}

340 Respondents indicated how much of the leaflet they had understood. Almost half of the respondents (49.4\%) reported having understood all of the information, with the remaining response categories being marked by between $4 \%$ and $12 \%$ of respondents.

\subsubsection{Compliance with instruction to retain leaflet}

350 Respondents answered this question, $64.3 \%$ of the respondents knew where their NSIL was, and $35.7 \%$ did not. The fact that $2 / 3$ of respondents reported that they had complied with the instruction to keep the leaflet represents a high rate of compliance with this instruction, particularly given the length of time since the last leaflet delivery. We know that cost of (effort involved in) compliance is a big predictor of compliance (e.g. Wogalter et al., 1989). The instruction to keep the leaflet is not a costly one to comply with and therefore we might expect compliance rates to be high.

\subsubsection{Memory for NSIL safety advisories}

529 Participants answered the section asking them to recall safety advisories. The safety advisories that respondents recalled were coded by two independent coders as either correct (the advice was correctly recalled, allowing for different wording); partial (the advice recalled deviated from its intended meaning e.g. 'Take Potassium Iodate tablets' instead of 'Take Potassium Iodate tablets if told to do so'); or absent (the advice was not recalled at all, or if the way in which it was recalled directly opposed the intended meaning).

The safety advisories most frequently recalled correctly were, 'close windows and doors' (68.7\%), 'go indoors' (54.9\%), 'listen to your local radio or TV' (52.7\%). These three advisories are the first that appear in the NSIL and so the relatively superior recall for these items may be evidence of the primacy effect in memory (e.g. Weisberg, 1980). This effect was demonstrated in an earlier study (Hellier et al., 2007) and taken together, the two findings add strength to the suggestion that the first instructional items in a list are the best remembered and should therefore be the most important ones. There may be alternative explanations for the superior recall of these items, however. For example, they may be simpler or be a better fit with respondents' underlying beliefs about appropriate behaviour in the event of a radiological incident (Pidgeon et al., 1992; Atman et al., 1994).

The remaining safety advisories were poorly remembered, with the percentage of respondents correctly recalling them ranging from $14.6 \%$ (do not use the phone), through $12.4 \%$ (take potassium iodate tablets if told to do so) and $11 \%$ (do not leave the area) to $7.1 \%$ (put out or damp down fires and boilers, shut down ventilation devices). Thus between 86 and $93 \%$ of respondents did not correctly recall these advisories. Two safety advisories produced relatively high levels of partial recall, which suggests that they may be overly complex and difficult to remember. These were 'take Potassium Iodate tablets if told to do so' (13.5\% partial recall) and 'put out or damp down fires and boilers, shut down ventilation devices' (8.2\% partial recall). In the former case, respondents did not remember that they should take Potassium Iodate tablets only when instructed to do so, and in the latter case respondents often did not remember the full range of things that should be shut down. Clarification and simplification of such multi-component items may aid recall in the future. 


\subsection{General discussion}

The baseline measurements indicated that periodic distribution of emergency preparedness literature as it is undertaken here is only partially effective. There were high levels of reported nonreceipt of the leaflet, and among those who did receive it, 51\% did not understand it all and their memory for the safety advice was very poor, ranging from an advisory being remembered by $68 \%$ of participants at best, to $7 \%$ at worst. More encouraging was the relatively high level of compliance with the instruction to keep the leaflet for future reference (64\%). Efforts to further increase and to stress compliance with this instruction may be a fruitful area for development - if recipients keep the leaflet, then they can refer to it when needed to clarify safety advice rather than having to remember individual advisories.

Clearly these findings have implications for the scheduling and delivery of emergency preparedness literature that are beyond the scope of this paper. What is also implied here is that it might be fruitful to consider changes to the design and content of the leaflet to encourage further reading, understanding, compliance and to improve recall of the safety advisories. There is a wealth of research from other domains that provides evidence as to what features of written communications make them readable, understandable, memorable and encourage compliance (e.g. Wogalter et al., 2002; Hellier et al., 2006). In the following section, that research is bought to bear in re-designing the NSIL.

\section{Intervention phase}

The rationale for the design of a trial leaflet was that it should represent anticipated 'best practice' on the basis of a review of existing research evidence. An extensive literature review was conducted to establish guidance for the design of emergency communications from published research; in addition, focus groups were held to evaluate the existing NSIL.

\subsection{Literature review of evidence}

A review of the academic and applied research literature over the last 20 years was conducted using the following databases; Web of Science, PsychLit, Medline, PsychINFO and Google Scholar. The search included research papers in scholarly journals as well as conference proceedings and abstracts. The search terms were selected to identify all articles relevant to the design, implementation and effectiveness of emergency communications. While there is some research which looks specifically at the design and effectiveness of emergency communications, there is also a wealth of research investigating warnings and persuasive communications more generally and these findings are likely to generalise to emergency communications. While it may be desirable to establish the extent to which some specific effects apply to emergency preparedness literature, the guidance that can be derived from the more general research provides a sensible starting place for the design and delivery of emergency preparedness literature.

Over 100 research papers with potential to inform the design of emergency communications were reviewed and distilled into preliminary guidance (Hellier et al., 2007). This guidance was organised according to the themes that emerged from the literature; the use of design variables (information content, wording, colour \& pictorials, formatting); mode of message delivery; influence of the attributed source of the information; audience factors (memory, mental models, risk perception, gender, tailoring); and other influences on compliance. Table 1 lists the research under each theme hat was most applicable to the design of the trial leaflet and details as to how it was applied.
Table 1

Research evidence that was applied to the design of the trial leaflet.

\section{Information content}

- Communications should include the following information; signal word, details of the hazard, explicit consequences of exposure, avoidance procedures (Wogalter et al., 1987, 2002; Mileti and Sorensen, 1990). While the use of a signal word was not appropriate here, the remainder of the material was organised so that details of the nature of the hazard, the consequences of exposure and avoidance instructions were clearly and explicitly presented.

- Scavenger hunts for information (which may result in inaccuracies) can be by avoided by not using overly short messages. Within that constraint, communications should be as short as possible to prevent recipients losing interest and being overloaded (Mileti and Sorensen, 1990). The trial leaflet (1548 words) was substantially shorter than the NSIL (2508 words). Recipients were directed to a source of authoritative additional information.

- The target audience should be involved in the design of communications (Rees et al., 2003). Focus groups were convened to evaluate the NSIL and feed into the design of the trial leaflet.

Wording

- The readability of a message should match the target audience's reading ability (Harrison and Bakker, 1998). Recommendations for public information materials are for a Flesch readability score of between 60 and 70 (Flesch, 1948) and a reading grade of 7-8 (Bradley et al., 1994). The readability of the text was difficult to simplify as REPPIR (2001) mandated the inclusion of much technical material. Some modification of the text and breaking long sentences into shorter ones enabled us to reduce the readability index from 61 to 56 and the reading grade from 8.9 to 8 .

- Highlighting the negative consequences of non-compliance (rather than the benefits of compliance) has greater impact (deTurck and Goldhaber, 1989; Levin et al., 1998). The negative consequences of non-compliance were emphasised when appropriate, e.g. 'You should not leave the area because if you do the roads may become gridlocked'.

- Definitive (rather than probabilistic) wording increases message believability, perceived hazard and appropriateness (e.g. Heaps and Henley, 1999). Definitive wording was used when appropriate, e.g. '...you will reduce the effects of exposure to radiation.'

- Explicit (rather than non-explicit) wording increases perceived warning appropriateness and behavioural compliance (Laughery et al., 1991; Frantz, 1994; Edworthy et al., 2004). Explicit wording was used when appropriate e.g. 'If you take the advice given in this leaflet, you will reduce the effects of exposure to radiation.'

\section{Colour and pictorials}

- Colour can convey different levels of hazard, with red conveying the highest levels of hazard (e.g. Chapanis, 1994). The colour scheme was presented in red and white.

- Pictorials can increase a warning's salience and improve comprehension (Wogalter et al., 2002; O'Hegarty et al., 2006). Pictorials were used to illustrate the advice elements.

\section{Message formatting}

- Increases in font size increase perceived hazard and readability (Adams and Edworthy, 1995). A minimum size 14 font was used throughout.

\section{Memory}

- Memory and information processing loads can be reduced by eliminating redundant information and ensuring its structure is logical and consistent with prior knowledge (Hancock et al., 2005). The text was structured into a tear-off section of summary advice, followed by sections of introduction, advice (with justification), additional information on children and food. Memory load was also reduced by reducing the overall length of the text.

- Repetition of a message can improve memory and persuasiveness (Cacioppo and Petty, 1989; Morrow et al., 1999). The safety advice was repeated, it was presented once in the summary section and again, with explanation and justification, in the main body of the leaflet.

\section{Compliance}

- The use of a personal pronoun has been shown to increase compliance (Edworthy et al., 2004). All safety advice was presented using the personal pronoun, e.g. 'You should close all windows and doors'.

- Encouraging the formation of implementation intentions and sub-goals promotes goal achievement and therefore compliance (Sheeran et al., 2005). To promote the goal of remembering the safety advice, recipients were presented with the sub-goals of tearing off the summary advice and sticking or storing it somewhere safe for future reference.

- To promote compliance warnings should emphasise the severity (rather than the likelihood) of the consequences of non-compliance (Wogalter and Barlow, 1990). The severity of the consequences of non-compliance were emphasised when appropriate e.g. 'You should not use mobile or landline telephones because the phone system could become overloaded. If this happens the emergency services will not be able to contact each other.' 


\subsection{Focus groups}

Community involvement in the design of emergency communications is a key recommendation to emerge from the research that was reviewed (Covello, 2003; Prue et al., 2003). The aim of the focus groups was to satisfy this recommendation by obtaining indepth evaluations of the NSIL from the target population in the PIZ, with a view to informing the design of the trial leaflet.

\subsubsection{Methodology}

6 Focus groups were convened in community centres inside the PIZ. Each focus group contained eight or nine participants, and was run by the same two facilitators.

3.2.1.1. Participants. 50 Participants were recruited by flyers distributed locally to the focus group venues. There were 25 males and 25 females, aged $18-73$ years $(M=43.5$ years $)$.

3.2.1.2. Procedure. Each participant was provided with a copy of the NSIL to study and refer to, and offered hot drinks and biscuits. Scripted questions were used by the facilitators to prompt discussion which probed participants' subjective impressions of the NSIL. Each session lasted an hour and was audio recorded. The audio recordings of the focus group discussions were transcribed and analysed using thematic analysis. Thematic analysis was selected as the most appropriate method for reducing the focus group transcripts into meaningful categories or themes (Braun and Clarke, 2006). The transcripts were coded into sub-themes which were grouped into overarching themes. The themes were re-applied to the transcripts by two independent coders and amended on the basis of their reflections. The full range of themes, wider than just comments on and improvements to the NSIL, were edited to include only those directly relevant to improving the leaflet.

\subsubsection{Results}

The themes (and sub-themes) to emerge from the thematic analysis were; commendations of the leaflet (design commendations, content commendations, emotional commendations), suggested general changes to the informational content (less information, clarification of information), requests for additional information on specified subjects (repeat information, add new information) and suggested changes to the formatting (facilitate storage, organisation, colour).

Many of the detailed proposals for change repeated those already being implemented on the basis of the research evidence (repetition of important information, clearer organisation of material, a simpler colour scheme, reduction in overall length). Focus group participants also requested specific information about the care of children in school, and so this was added to the trial leaflet. Additionally, participants pointed out specific text in the NSIL that was confusing or required further clarification (for example, participants were unclear whether the instruction 'Do not use the phone' included mobile telephones, and also when they should use the emergency numbers listed in the NSIL if they could not use the phone). In the trial leaflet, these and other specific points were clarified, and a section on evacuation was removed as this was felt to dilute the message to 'stay in'. Participants also had clear preferences for facilitating retention of the leaflet, and on the basis of their suggestions it was laminated to improve durability, and presented with a one page tear-off front section of summary information for posting to a notice board or door.

\subsection{The trial leaflet}

The trial leaflet was designed by incorporating as many of the research-based guidelines and focus group suggestions for improvements as possible (as detailed in Table 1 and above), while not compromising the mandated requirement to retain the presentation of particular information (REPPIR, 2001). Broadly speaking, the trial leaflet was substantially shorter, had a lower reading age and was more explicitly structured using headings and sub-headings than the original. In addition, it was generally expressed in definitive, explicit language, using the personal pronoun, was explicit about the safety advice and the rationale for it, and contained additional sections requested by potential recipients in focus groups. The trial leaflet was more explicit than the original in providing summary advice, presenting it as a tearoff section to keep for future reference, and in instructing participants to do this.

\section{Subjective evaluations of the NSIL and the trial leaflet}

\subsection{Introduction}

In June 2008 the site operator delivered the NSIL to all households in the PIZ, as mandated by REPPIR (2001). In order to facilitate direct comparison of the leaflets, the trial leaflet was also delivered to 1350 households in the PIZ (that had also received the most recent delivery of the NSIL) in the same month.

\subsection{Method}

\subsubsection{Participants}

1350 Households which had received both a copy of the trial leaflet and a copy of the NSIL leaflet that was delivered in 2008.

\subsubsection{Materials}

A questionnaire was designed to assess whether or not respondents had received the leaflets and had read and understood them. A direct measure of compliance with the safety information was obtained by asking respondents whether or not they still had their leaflets. Respondents were also asked which leaflet they preferred. For each question the response format was a forced choice, requiring respondents to indicate either one of the leaflets or 'no preference'.

\subsubsection{Procedure}

The questionnaires and letters of introduction were hand delivered to the 1350 households. The questionnaires were delivered by two distributors on two consecutive days in July 2008 (one month after the delivery of the leaflet). They were posted through letter boxes ensuring that multiple occupancy households were provided with a questionnaire for each residential unit. To encourage quick return of the data, a freepost envelope was included with the questionnaire and the respondents were invited to take part in a prize draw as an incentive.

\subsection{Results $\mathcal{E}$ discussion}

There was a very low response rate, with only 112 questionnaires returned (c. 8\%). Subsequent enquires from the general public to our distribution team, querying the whereabouts of the NSIL, revealed that many of the sample who should have received the NSIL (2008) had not done so. Thus many households who were invited to participate in this study could not do so as they had only received one leaflet, the trial leaflet, and had nothing to compare it with. Of the questionnaires that were returned, only 57 respondents reported that they had received both leaflets, thus it was only possible to compare responses to the two leaflets for these 57 respondents. 


\subsubsection{Which leaflet was read?}

Whether or not the leaflets were read was a measure of their effectiveness since reading the material is a necessary pre-requisite to understanding it and complying with it. The majority of the 57 respondents (94\%) read both leaflets, and thus there was no real difference between the two leaflets in terms of whether or not they were read.

\subsubsection{Which leaflet was easiest to understand?}

Whether or not the leaflets were understood was a measure of their effectiveness since understanding the material is a necessary pre-requisite to complying with it. A larger proportion of respondents found the trial leaflet easier to understand (59\%) than the NSIL (24\%). $17 \%$ of Respondents expressed no preference.

\subsubsection{Which leaflet was kept?}

Whether or not the leaflets were kept was a direct measure of compliance since both leaflets instructed recipients to keep the information for future reference. The majority of respondents (86\%) kept both leaflets, and thus there was no real difference between the two in terms of compliance with that instruction.

\subsubsection{Which leaflet was preferred?}

A larger proportion of respondents (57\%) preferred the trial leaflet, as compared with the NSIL (31\%), the remainder expressed no preference. The most common reason cited in the free response section for preferring the trial leaflet was that it was simpler and easier to understand. Other reasons reported were that it was more informative, offered a pin-up summary, had preferred pictures and a preferred layout. The most common reasons cited for preferring the NSIL was familiarity, preferred layout, preferred pictures.

\subsection{General discussion}

The primarily subjective measurements taken here suggest some evidence of an advantage for the trial leaflet. When differences are observed between responses to the NSIL and the trial leaflet, the trial leaflet was considered more understandable and was preferred. While there were no differences between the two leaflets on some metrics, there were no instances in which the NSIL was preferred over the trial leaflet. This support for the trial leaflet, designed according to research-led guidance and feedback from target recipients, is encouraging with respect to the use of researchbased guidelines to inform the design of emergency communications, but further research to validate emergency communications designed in this way is clearly needed, collecting objective measures of memory and understandability.

\section{Objective evaluations of the NSIL and the trial leaflet}

\subsection{Introduction}

The work described here seeks to enhance the evaluation of the two emergency communication leaflets by collecting objective data about people's relative performance with them. Participants were given time to study one of the two leaflets in an experimental setting. Objective measures of memory were recorded once after the study period and again either one week or four weeks later. Thus memory for the safety advice presented in the two leaflets was directly compared. When considering the design of emergency preparedness information such as the leaflets considered here, a memory measure is particularly useful - one of the things that distinguishes preparedness literature from other emergency communications is that preparedness literature is distributed prior to an event and must therefore be remembered. Measures of behavioural intention, understandability and subjective preference were also taken.

\subsection{Method}

\subsubsection{Design}

Participants studied either the NSIL or the trial leaflet and their memory was assessed at the study period and then either one week or one month after study. The main dependant variables were behavioural intention in relation to the safety advisories, selfreported understanding of the advice, subjective preference for the leaflets and a repeated measure of memory for the advisories. The analyses not involving memory were simple one-way ANOVAs with leaflet (NSIL, Trial) as the single between subjects factor. The memory scores were analysed with mixed design ANOVAs with the repeated measures factor Time $(1,2)$ and between subjects factors Leaflet (NSIL, Trial) and Time Delay (1 week, 1 month).

\subsubsection{Participants}

302 Participants aged $18-90(M=39.5$ years $)$ were recruited via posters displayed in the university, from flyers distributed in the city centre and through the School of Psychology participation pool. Participants living in the PIZ were excluded as they would have already seen at least one of the leaflets.

\subsubsection{Materials}

Intended compliance to each safety advisory was measured using Likert-type scales ranging from 1 (compliance extremely unlikely) to 8 (extremely likely), and self-reported understanding for each advisory was measured on scales ranging from 1 (do not understand) to 8 (understand completely). Subjective preferences were also recorded by asking participants to indicate readability, completeness (whether participants felt that had all of the information they needed), whether there was specific information missing and their trust in the leaflet - all on Likert scales from 1(negative) to 8 (positive). Participants were also asked to indicate the best and worst things about the leaflet they studied. Paper mazes were used as a distracter task after the leaflet study period. Memory for the advisories was measured by free recall.

\subsubsection{Procedure}

Participants were assigned to one of the four experimental conditions so that the numbers of males and females and the mean age was approximately equal across conditions. They were given either the NSIL or the trial leaflet and were asked to imagine that it had been delivered to their home and contained important safety advice, they were asked to study the leaflet carefully. After a $20 \mathrm{~min}$ study period, participants completed the measures of intended compliance, self-reported understanding and subjective preference. Participants were then given a distracter task for 15 min (a selection of mazes to complete) and then asked to free recall as much of the safety advice as they could. Participants were contacted by phone either one or four weeks after the initial session and asked to free recall the safety advisories again.

\subsection{Results $\mathcal{E}$ discussion}

\subsubsection{Intended compliance}

Generally the behavioural intention to comply with the advice was quite high for both leaflets, ranging from 7.5 (close doors and windows) to 5.5 (do not use telephone). ANOVAs revealed that leaflet was not a significant predictor of intended compliance for any of the advisories. 


\subsubsection{Self-reported understanding of the advice}

Participants scored much lower for self-reported understanding of the advice to take Potassium Iodate tablets $(M=6.7)$ than for the other advisories $(M=7.2)$ but again, ANOVAs revealed that leaflet was not a significant predictor of self-reported understanding for any of the advisories.

\subsubsection{Subjective preferences for the leaflets}

ANOVA revealed that the trial leaflet $(M=7.4)$ was significantly easier to read than the NSIL $(M=6.9),(F(1,295)=19.347, p<.001$, $r=.27)$. There was no significant difference between the leaflets on missing information $(F(1,295)=.106, p=.745)$ or on trustworthiness $(F(1,298)=1.931, p=.166)$, but the NSIL was judged to contain more unnecessary information than the trial leaflet $(F(1,296)=$ 26.33, $p<.001, r=.286)$.

\subsubsection{Memory for safety advisories}

Memory for the advice was in the form of free recall at the time of study (T1) and at the time of the telephone interview (T2). If a piece of advice was remembered by a participant it was given a score of one and if not remembered a score of zero. Memory scores were out of a maximum of 19 as these were the safety advisories specified in the leaflets (go in, stay in, close doors, close windows, put out fires, switch off boilers, switch off ventilation, listen to TV, listen to radio, do not use phone/landlines, do not use mobile phone, do not leave the area, follow instructions from authorities, take potassium iodate tablets, only if instructed to do so, go to the nearest building, keep leaflet safe, keep pets indoors and don't collect children from school).

The mean memory score was calculated for each safety advisory, by leaflet. Fig. 1 displays the mean memory scores at T2. Overall memory performance varied greatly between the different pieces of advice, with 'Go in' being best remembered and 'go to the nearest building' or ' follow instructions' being the worst remembered, regardless of the leaflet studied leaflet. (Although 'keep the leaflet safe' scored very low for memory, participants reported that this was because they were asked to remember what to do in an emergency, and they judged that this advice was about actions to take prior to an emergency, therefore they did not report it). For simplicity we report the results for the items where the main effect of leaflet was significant (i.e. the effect of leaflet on memory averaged over T1 and T2 and over both Time Delay groups) and for these cases any higher order interactions involving leaflet that could qualify the interpretation of these main effects. The following items showed an advantage for the Trial leaflet:

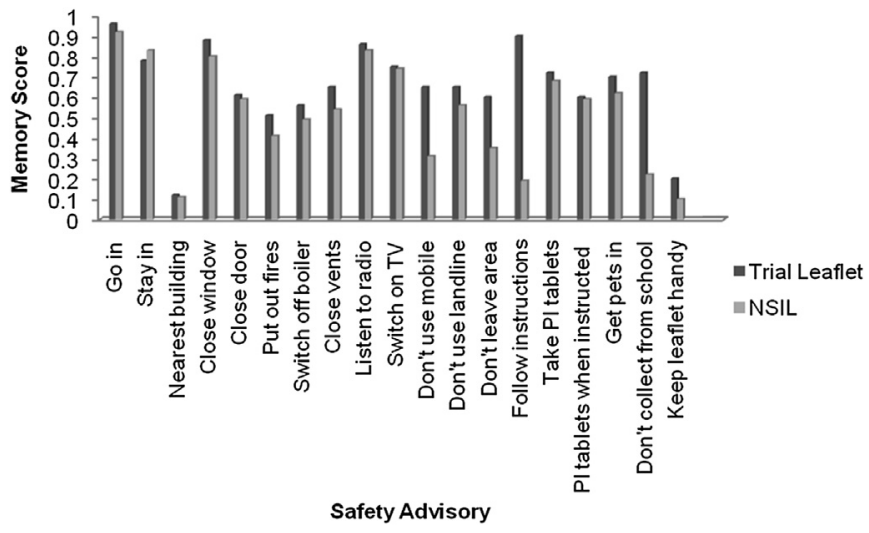

Fig. 1. Mean memory scores for both leaflets at $\mathrm{T} 2$.
Going inside. Only the main effect of Leaflet was significant $\left(M_{\text {Trial }}=.99, M_{\mathrm{NSIL}}=.963, F(1,298)=5.01, p=.026, r=.13\right)$, Closing windows. The main effect of leaflet was significant $\left(M_{\text {Trial }}=.937, M_{\mathrm{NSIL}}=852, F(1,298)=9.47, p=.002, r=.16\right)$. In addition leaflet interacted with Time Delay, $F(1,298)=5.3$, $p=.02$. The interaction pattern indicated that whilst there was very little difference between the two leaflets for the 1 month group $\left(M_{\text {Trial }}=.920, M_{\mathrm{NSIL}}=.899\right)$ there was a large difference for the 1 week group $\left(M_{\text {Trial }}=.954, M_{\text {NSIL }}=.805\right)$,

Closing vents. The main effect of Leaflet was the only significant effect $\left(M_{\text {Trial }}=.775, M_{\mathrm{NSIL}}=.526\right), F(1,298)=44.28, p<.001$, $r=.12$,

Not using mobile phones. The effect of Leaflet was highly significant $\left(M_{\text {Trial }}=.937, M_{\text {NSIL }}=.852, F(1,298)=9.47, \quad p=.002\right.$, $r=.36)$. In addition leaflet interacted with test time $(F(1,298)=$ $6.18, p=.013$ ) with the interaction pattern indicating that the NSIL leaflet suffered a larger decrease $(-.37)$ in memory from T1 to T2 than the Trial leaflet $(-.2)$.

Not collecting children from school. Leaflet produced a highly significant effect $\left(M_{\text {Trial }}=.778, M_{\mathrm{NSIL}}=.222, F(1,298)=190.43\right.$, $p=<.001, r=.62)$. In addition leaflet interacted with test time, $F(1,298)=6.6, p=.011$ with the interaction pattern indicating that whilst the Trial leaflet scores decreased by .06 from T1 to T2 the NSIL leaflet actually produced a slight increase in scores of .07.

The following items showed a memory advantage for the NSIL leaflet:

Following instructions. Leaflet was highly significant $\left(M_{\text {Trial }}=.199, M_{\mathrm{NSIL}}=.335, F(1,298)=13.279, p=<.001, r=.21\right)$. No interactions with the leaflet effect were present.

Staying inside. The effect of leaflet was significant $\left(M_{\text {Trial }}=.832\right.$, $\left.M_{\mathrm{NSIL}}=.901, F(1,298)=6.095, p=.014, r=.14\right)$. There were no interactions with Leaflet.

\subsubsection{Overall measure of memory}

In order to investigate the impact of leaflet design on memory for all of the advice contained in the leaflet and to consider the possibility of an interaction between leaflet and time period on memory (to see if one leaflet performed better over time than the other one) the scores for each of the 19 pieces of advice were collated to get an overall score for memory for all of the advice at T1 and T2. The overall memory scores are shown in Fig. 2. As expected

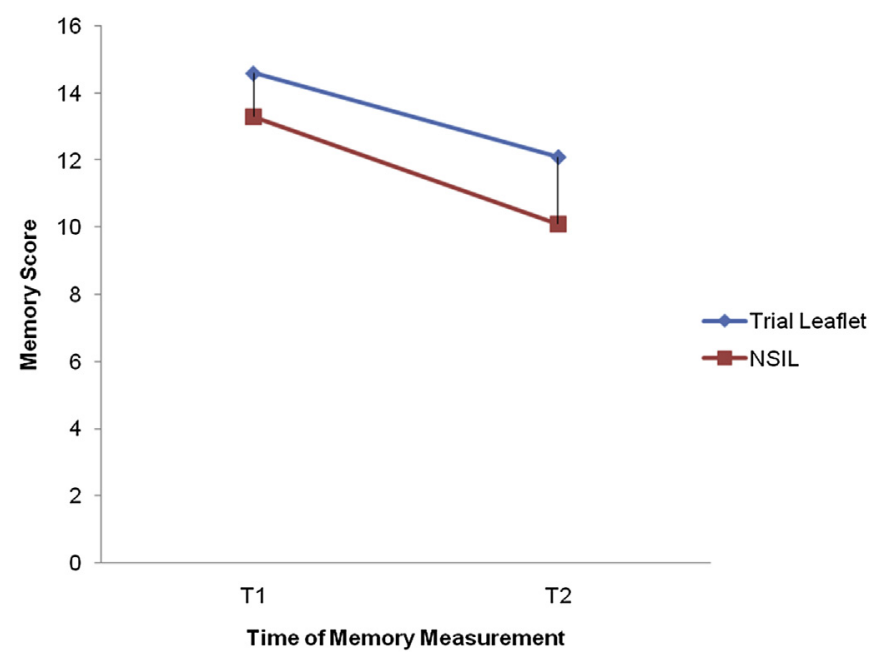

Fig. 2. Overall memory scores for the two leaflets. 
overall memory scores declined from $\mathrm{T} 1$ to $\mathrm{T} 2 \quad\left(M_{\mathrm{T} 1}=13.9\right.$, $\left.M_{\mathrm{T} 2}=11.0, F(1,298)=383.0, p<.001\right)$. As expected this decline was more pronounced for the 1 month group $(-3.7)$ than the 1 week group $(-2.1)$. The overall memory score for the trial leaflet $(M=13.21)$ was higher than for the NSIL $(M=11.64, F(1,298)=$ $57.6, p=<.001$ ), there were no interactions between leaflet and any other factor.

\subsection{Discussion}

The trial leaflet, designed using research-based guidelines, outperformed the NSIL in terms of overall memory for the advice elements. Besides being better remembered than the NSIL, the trial leaflet was also judged as being easier to read and to contain less unnecessary information. The trial leaflet was shorter and had some technical information removed, and this probably resulted in it being easier to read. Interestingly, the reduced length and ease of reading did not influence intended compliance, self-reported understanding, or the trust in the leaflets as there were no differences in any of these measures between the trial and the NSIL leaflets. Thus the trial leaflet, designed using research-based guidelines, out-performed the NSIL leaflet in terms of overall memory for the advice elements and readability, with no loss in trust, intended compliance, or understandability.

\section{General discussion}

The study described here provided an excellent 'real world' opportunity to explore issues around the distribution and design of emergency preparedness literature.

The baseline measurement phase of study allowed us to consider the effectiveness of periodic distributions of preparedness literature, as well as to evaluate the extant NSIL. When we measured our respondents in December 2007, they were towards the end of a 3-year distribution cycle, and we could assess the effectiveness of the leaflet 2.5 years since its last distribution. What was clear from the data is that not all of the residents who should have received the NSIL reported having done so. Even among the majority group who had been resident in their homes for more than 5.5 years (and therefore should have received the leaflet twice), 22\% reported not having received the leaflet. Among respondents who had been resident for up to 5.5 years (and therefore should have received one distribution of the leaflet) the proportion of selfreported non-receipt rose to $46 \%$. These issues were again found when we surveyed residents after the 2008 distribution of the NSIL, of the 1350 households surveyed, only a shocking $4 \%$ reported having received the NSIL.

It is clear then that many residents in the PIZ are not, or do not believe themselves to be, in receipt of the emergency preparedness literature that they should have. This calls into question the adequacy of emergency preparedness literature distributed in this way, and suggests that it is failing the very first necessary requirement for warning information, that it is perceived. It may be that three years is too long between distribution cycles, with the consequence that residents forget they have received a leaflet. Alternatively, residents may not notice a leaflet distribution - respondents in the focus group phase of the study indicated that the envelope in which the leaflet was delivered was too easily confused with junk mail and thus may not be opened. It is also possible that the distribution process itself is at fault. At the very least this study suggests a need to verify the delivery of emergency preparedness literature.

In addition to low levels of receipt of the leaflet among the target population, memory for the safety advisories was also poor. The only items on the NSIL that were relatively well remembered after 2.5 years were the first three items presented, 'close windows'
(68\%), 'go indoors and stay there' (54\%) and 'listen to the television and radio' (52\%). The remaining safety instructions were very poorly recalled, with between only $14.6 \%$ and $7.1 \%$ of respondents remembering each item. Even in the lab based study recall of the safety advisories was imperfect and some pieces of advice were more commonly remembered then others.

Some of the problems with overall memory for safety advisories can be ameliorated if recipients keep the emergency communication for future reference, as they are advised to do. Compliance with this advisory does seem to be encouraging, at $64 \%$ in the baseline measurement sample and $86 \%$ in the subjective evaluation sample. We suggest that focussing on this advisory and means of maximising compliance with it should be a priority for the design of emergency preparedness literature. Enhanced memory load is one thing that differentiates emergency preparedness literature (distributed in advance of when it is needed) from more traditional warning information (presented at the time of exposure to the risk, rather than in advance). If recipients can remember to keep emergency preparedness literature, then they can refer to it when needed and the memory load is lifted. For the other, more technical safety advisories it was only possible to measure intended compliance, and while levels of intended compliance with all of the advisories was high, it remains a subject of some debate the extent to which such intentions or expectations might predict behaviour (e.g. Ajzen, 1991; Godin et al., 2005), with some evidence to suggest that the relationship between behavioural expectation and behaviour might be particularly weak for unfamiliar behaviours (Kang et al., 2007).

Both the baseline measurement and subjective evaluations were plagued by low response rates and this must be borne in mind when interpreting their findings. While we have no formal information on the non-responders, we might expect them to be less engaged with the emergency preparedness literature and so the rates of receipt, and engagement with materials to be lower in the population than in our sample. The low response rates also sound a note of caution to the calls for community input to the development and testing of emergency communication materials (e.g. Rees et al., 2003; Covello, 2003; Prue et al., 2003). Clearly there is a need to engender widespread community engagement to ensure that inputs are representative.

Overall we have found support for the use of research-based guidelines in the design of emergency preparedness literature. The trial leaflet, designed to reflect research evidence on effective warning and persuasive communications, was rated as being easier to read and understand, was preferred, and was judged to contain less unnecessary information. In addition, memory for the advice was better when participants studied the trial leaflet. Specific pieces of advice that were particularly well remembered after study of the trial leaflet as opposed to the NSIL were: not using mobile phones, not leaving the area, not collecting children from school and following instructions. The trial leaflet was shorter and had some technical information removed, which probably resulted in it being easier to read and understand, but importantly, the reduced length and ease of reading did not influence intended compliance, or the trust in the leaflets. There were no differences in any of these measures between the trial leaflet and the NSIL. The measures taken here, of readability, understandability and memorability indicate the important necessary conditions for successful emergency communication (Sanders and McCormick, 1992). However, although we have measured intended compliance with 19 specific advisories and compliance with one non-technical advisory (retention of the leaflet), there clearly remains research to do in delineating the determinants of compliance in a crisis situation.

It is worth noting that behavioural intention for the advice to not use the phone was lower than for the other pieces of advice. This is consistent with the findings of Page et al. (2008) who found 
that being unable to contact family in the aftermath of the London terrorist bombings (7 July 2005) was an important predictor of distress and that $70 \%$ of their sample had made plans about contacting family in the event of a future emergency. Overall behavioural intention to not pick children up from school was also lower than for most of the other pieces of advice, again reflecting the findings of Page et al. (2008) who found that $26 \%$ of parents of school age children tried to collect then early from school on the day of the London Bombings, 7th July 2005. In the trial leaflet, where the rationale for the advice not to use mobile phones and not to collect children was clearly explained, there was a marked increase in the behavioural intention to comply with these advisories.

\section{References}

Adams, A.S., Edworthy, J., 1995. Quantifying and predicting the effects of basic text display parameters on the perceived urgency of warning labels: tradeoffs involving font size, border weight and colour. Ergonomics 38 (11), 2221-2237.

Ajzen, I., 1991. The theory of planned behaviour. Organ. Behav. Hum. Decis. Process. 50, 179-211.

Atman, C.J., Bostrom, A., Fischhoff, B., Morgan, M.G., 1994. Designing risk communications: completing and correcting mental models of hazardous processes, part I. Risk Anal. 14 (5), 779-788.

Barlow, R., Wogalter, M.S., 1993. Alcoholic beverage warnings in magazine and television advertisements. J. Consum. Res. 20 (1), 147-156.

Bartholomew, L., Parcel, G., Kok, G., Gottlieb, N., 2001. Intervention Mapping: Designing Theory and Evidence Based Health Promotion Campaigns. Mayfield Publishing Company, Mountain View, CA.

Becker, S., 2011. Risk communication and radiological/nuclear terrorism: a strategic view. Health Phys. 101 (5), 551-558.

Becker, S., 2004. Emergency communication and information issues in terrorist events involving radioactive materials. Biosecur. Bioterr. Biodef. Strategy, Pract. Sci. 2 (3), 195-207.

Bernardini, C., Ambrogi, V., Fardella, G., Perioli, L., Grandolini, G., 2001. How to improve the readability of the patient package leaflet: a survey of the use of colour, print size and layout. Pharmacol. Res. 43 (5), 437-444.

Berry, D., Raynor, T., Knapp, P., Bersellini, E., 2004. Over the counter medicines and the need for immediate action: a further evaluation of European Commission recommended wordings for communicating risk. Patient Educ. Counsel. 53 (2),129-134.

Bier, V.M., 2001. On the state of the art: risk communication to the public. Reliab. Eng. Syst. Saf. 71 (2), 139-150.

Bostrom, A., Atman, C.J., Fischhoff, B., Morgan, M.G., 1994. Evaluating risk communications: completing and correcting mental models of hazardous processes part II. Risk Anal. 14 (5), 789-798.

Bradley, B., Singleton, M., Po, A., 1994. Readability of patient information leaflets on over the counter (OTC) medicines. J. Clin. Pharm. Ther. 19, 7-15.

Braun, V., Clarke, V., 2006. Using thematic analysis in psychology. Qual. Res. Psychol. 3 (2), 77-101.

Braun, C.C., Silver, N.C., 1995. Interaction of signal words and color on warning labels: differences in perceived hazard and behavioural compliance. Ergonomics 38, 2207-2220.

Cacioppo, J.T., Petty, R.E., 1989. Effects of message repetition on argument processing, recall, and persuasion. Basic Appl. Psychol. 10 (1), 3-12.

Centres for Disease Control \& Prevention, 2002. Crisis and emergency risk communication. http://www.bt.cdc.gov/cerc/pdf/CERC-SEPT02.pdf.

Chapanis, A., 1994. Hazards associated with three signal words and four colors on warning signs. Ergonomics 37, 265-276.

Covello, V., 2003. Best practices in public health risk and crisis communication. J. Health Commun. 8 (S1), 5-8.

Costello, A., Hellier, E., Edworthy, J., Coulson, N., 2002. Can food label design characteristics affect perceptions of genetically modified food? In: McCabe, P. (Ed.), Contemporary Ergonomics. Taylor \& Francis, London, pp. 442-446.

Davidson, D.J., Freudenburg, W.R., 1996. Gender and environmental risk concerns a review and analysis of available research. Environ. Behav. 28 (3), 302-339.

Davie, R., Panting, C., Charlton, T., 2004. Mobile phone ownership and usage among pre-adolescents. Telemat. Inf. 21 (4), 359-373.

deTurck, M.A., Goldhaber, G.M., 1989. Effectiveness of product warnings: effects of language valence, redundancy and color. J. Prod. Liabil. 12, 93-102.

Edworthy, J., Hellier, E., Lambell, N., Grey, C., Aldrich, K., Lee, A., 2004. Linguistic and location effects in compliance to pesticide warning labels. Hum. Factors 46, 1-21.

Flesch, R., 1948. A new readability yardstick. J. Appl. Psychol. 32, 221-233.

Frantz, J.P., 1994. Effect of location and procedural explicitness on user processing of and compliance with product warnings. Hum. Factors 36, 532-546.

Furnham, A., Gunter, B., Green, A., 1990. Remembering science: the recall of factual information as a function of the presentation mode. Appl. Cogn.. Psychol. 4, 203-212.

Godin, G., Conner, M., Sheeran, P., 2005. Bridging the intention-behaviour gap: the role of moral norm. Br. J. Soc. Psychol. 44, 497-512.

Grabe, E., Kamhawi, R., 2006. Hard wired for negative news? Gender differences in processing broadcast news. Commun. Res. 33 (5), 346-369.
Hancock, H.E., Fisk, A.D., Rogers, W.A., 2005. Comprehending product warning information: age-related effects and the roles of memory, inferencing, and knowledge. Hum. Factors 47 (2), 219-234.

Harrison, S., Bakker, P., 1998. Two new readability predictors for the professional writer: pilot trials. J. Res. Read. 21 (2), 121-138.

Heaps, C.M., Henley, T.B., 1999. Language matters: wording considerations in hazard perception and warning comprehension. J. Psychol. 133, 341-351.

Hellier, E., Edworthy, J., Derbyshire, N., Costello, A., 2006. Considering the impact of medicine label design characteristics on patient safety. Ergonomics 49, 617-630.

Hellier, E., Edworthy, J., Aldrich, K., Costello, A., Reid, F., Reid, D., 2007. Factors Influencing Information Spread and Reliability. In: Experimental Series 2: the Effect of Message Format and Content Variables on Perception and Recall of Emergency Messages. Unpublished report for the Home Office, ref 43/05/77.

Henderson, J., Henderson, L., Raskob, G., Boatright, D., 2004. Chemical (VX) terrorist threat: public knowledge, attitudes, and responses. Biosecur. Bioterr. Biodef. Strategy, Pract. Sci. 2 (3), 224-228.

Kang, J.E., Lindell, M.K., Prater, C.S., 2007. Hurricane evacuation expectations and actual behaviour in hurricane Lili. J. Appl. Soc. Psychol. 37, 881-897.

Knapp, P., Raynor, T., Berry, D., 2004. Comparison of two methods of presenting risk information to patients about the side effects of medicines. Qual. Saf. Health Care 13 (3), 176-180.

Krishnamurthy, P., Carter, P., Blair, E., 2001. Attribute framing and goal framing effects in health decisions. Organ. Behav. Hum. Decis. Process. 85 (2), 382-399.

Laughery, K.R., Rowe-Halbert, A.R., Young, S.L., Vaubel, K.P., Laux, L.F., 1991. Effects of explicitness in conveying severity information in product warnings. In: Proceedings of the Human Factors 42nd Annual Meeting. Human Factors Society, Santa Monica, CA, pp. 1088-1092.

Leahy, W., Chandler, P., Sweller, J., 2003. When auditory presentations should and should not be a component of multimedia instruction. Appl. Cogn. Psychol. 17, 401-418.

Lemyre, L., Turner, M.C., Lee, J.E.C., Krewski, D., 2006. Public perception of terrorism threats and related information sources in Canada: implications for the management of terrorism risks. J. Risk Res. 9 (7), 755-774.

Levin, I.P., Schneider, S.L., Gaeth, G.J., 1998. All frames are not created equal: a typology and critical analysis of framing effects. Organ. Behav. Hum. Decis. Process. 76 (2), 149-188.

Lindell, M.K., Perry, R.W., 1992. Behavioural Foundations of Community Emergency Planning. Hemisphere, Washington, DC.

Lindell, M.K., Perry, R.W., 2004. Communicating Environmental Risk in Multi-Ethnic Communities, Sage, Thousand Oaks, CA.

Lindell, M.K., Perry, R.W., 2012. The protective action decision model: theoretical modifications and additional evidence. Risk Anal. 32, 616-632.

MacGregor, D.G., Slovic, P., Morgan, M.G., 1994. Perception of risks from electromagnetic fields: a psychometric evaluation of a risk-communication approach. Risk Anal. 14 (5), 815-828.

Mileti, D.S., Sorensen, J.H., 1990. Communication of Emergency Public Warnings, Oak Ridge National Laboratory, Colorado State University.

Morrow, D., Leirer, V.O., Carver, L.M., Tanke, E.D., McNally, A.D., 1999. Repetition improves older and younger adult memory for automated appointment messages. Hum. Factors 41 (2), 194-204.

Moseley, T.H., Wiggins, M.N., O'Sullivan, P., 2006. Effects of presentation method on the understanding of informed consent. Br. J. Ophthalmol. 90, 990-993.

O'Hegarty, M., Pederson, L.L., Nelson, D.E., Mowery, P., Gable, J.M., Wortley, P., 2006. Reactions of young adult smokers to warning labels on cigarette packages. Am. J. Prev. Med. 30 (6), 467-473.

Page, L., Rubin, J., Amolt, R., Simpson, J., Wesely, S., 2008. Are Londoners prepared for an emergency? A longitudinal survey following the London bombings. Biosecur. Bioterr. Biodef. Strategy, Pract. Sci. 6 (4), 309-319.

Parker, R., Gazmararian, J., 2003. Health literacy: essential for health communication. J. Health Commun. 8 (S1), 116-118.

Peek, L., Mileti, D.M., 2002. The history and future of disaster research. In: Bechtel, R.B., Churchman, A. (Eds.), Handbook of Environmental Psychology. Wiley, New York, pp. 511-524.

Pidgeon, N., Hood, C., Jones, D., Turner, B., Gibson, R., 1992. Royal Society Report on Risk: Analysis, Perception \& Management. The Royal Society, London.

Prue, C., Lackey, C., Swenarski, L., Gantt, J., 2003. Communication monitoring: shaping CDC's emergency risk communication efforts. J. Health Commun. 8 (S1), 35-49.

REPPIR, 2001. Radiation (Emergency Preparedness and Public Information). No 2975.

Rudd, R., Comings, J., Hyde, J., 2003. Leave no one behind: improving health and risk communication through attention to literacy. J. Health Commun. 8 (S1), 104-115.

Sanders, M., McCormick, E., 1992. Human Factors in Engineering and Design. McGraw-Hill Science.

Sheeran, P., Webb, T.L., Gollwitzer, P.M., 2005. The interplay between goal intentions and implementation intentions. Personal. Soc. Psychol. Bull. 31 (1), 87-98.

Shiv, B., Britton, J.A.E., Payne, J.W., 2004. Does elaboration increase or decrease the effectiveness of negatively versus positively framed messages? J. Consum. Res. 31, 199-208.

Shore, D., 2003. Communicating in times of uncertainty: the need for trust. J. Health Commun. 8 (S1), 13-14.

Singh, S.N., Mishra, S., Bendapudi, N., Linville, D., 1994. Enhancing memory of television commercials through message spacing. J. Mark. Res. XXXI, 385-392. 
Slovic, P., 1993. Perceived risk, trust, and democracy. Risk Anal. 13 (6), 675-682. Sorensen, J.H., 2000. Hazard warning system: review of 20 years of progress. Nat. Hazards Rev. 1, 119-125.

Sorensen, J.H., Vogt, B.N., Mileti, D.S., 1987. Evacuation: an Assessment of Planning and Research. Federal Emergency Management Agency, Washington, DC.

Taylor, V.A., Bower, A.B., 2004. Improving product instruction compliance: "if you tell me why, I might comply". Psychol. Mark. 21 (3), 229-245.

Vanderford, M., 2003. Communication lessons learned in the emergency operations centre during CDC's anthrax response: a commentary. J. Health Commun. 8 (S1), 11-12.

Weisberg, R.W., 1980. Memory, Thought, \& Behaviour. Oxford University Press, New York.

Wogalter, M.S., Godfrey, S.S., Fontenelle, G.A., Desaulniers, D.R., Rothstein, P.R., Laughery, K.R., 1987. Effectiveness of warnings. Hum. Factors 29 (5), 599-612.

Wogalter, M., Allison, S., McKenna, N., 1989. Effects of cost and social influence on warning compliance. Hum. Factors 31 (2), 133-140.
Wogalter, M.S., Barlow, T., 1990. Injury severity and likelihood in warnings. In: Proceedings of the Human Factors 34th Annual Meeting. Human Factors Society, Santa Monica, CA, pp. 580-583.

Wogalter, M.S., Young, S., 1991. Behavioural compliance to voice and print warnings. Ergonomics 34, 78-89.

Wogalter, M., Dejoy, D., Laughery, K., 1999. Warnings and Risk Communication. Taylor \& Francis, London.

Wogalter, M., Conzola, V., Smith-Jackson, T., 2002. Research-based guidelines for warning design and evaluation. Applied Ergonomics 33, 219-230.

Wray, R., Jupka, K., 2004. What does the public want to know in the event of a terrorist attack using plague? Biosecur. Bioterr. Biodef. Strategy, Pract. Sci. 2 (3), $208-215$.

Wray, R., Kreuter, M., Jacobsen, H., Clements, B., Evans, G., 2004. Theoretical perspectives on public communication preparedness for terrorist attacks. Fam. Commun. Health 27 (3), 232-241. 